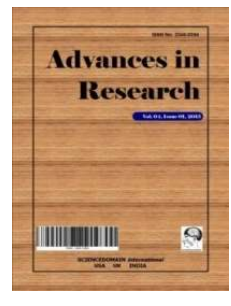

Advances in Research

5(6): 1-8, 2015, Article no.AIR.20496

ISSN: 2348-0394

SCIENCEDOMAIN international

www.sciencedomain.org

\title{
A Testing Procedure to Analyse the Effect of Window Coverings
}

\author{
Dariusz Alterman $^{1^{*}}$ and Stephen O'Keeffe ${ }^{2}$ \\ ${ }^{1}$ School of Engineering, Faculty of Engineering and Built Environment, University of Newcastle, \\ University Drive, Callaghan N.S.W 2308, Australia. \\ ${ }^{2}$ Classic Blinds and Shutters Company, Australia.
}

Authors' contributions

This work was carried out in collaboration between both authors. Author SO performed all tests using classic blinds and shutters facilities. Author DA managed and verified the analyses of the window coverings, performed the literature searches and composed the final draft. Both authors read and approved the final manuscript.

Article Information

DOI: $10.9734 / \mathrm{AIR} / 2015 / 20496$

(1) Enedir Ghisi, Federal University of Santa Catarina, Department of Civil Engineering, Florianópolis-SC,

Brazil.

Reviewers

(1) Logerais Pierre-Olivier, Université Paris-Est Créteil, France. (2) Anonymous, National Cheng Kung University, Taiwan. Complete Peer review History: http://sciencedomain.org/review-history/11304

Original Research Article

Received $30^{\text {th }}$ July 2015 Accepted $29^{\text {th }}$ August 2015 Published $6^{\text {th }}$ September 2015

\begin{abstract}
The paper presents the procedure and facilities used to empirically assess the thermal performance of the window coverings subjected to the radiation from the light source. The ability of the window coverings to minimize the heat gain on the internal environment of the testing chambers is also discussed. Two identical chambers have been built whilst maintaining a recommended window to floor space ratio, one chamber has a glass pane and its replica has similar glass and a system to fit various window coverings.

It was found that the thermal conductivity of window covering materials (and R-value indirectly) seemed to be less significant because the heat was reflected back to the external environment and the radiation was a major driver of the thermal performance. The entire heat transfer process is then much more influenced by the color of the window coverings, as the darker colors absorb more heat from the radiation. The lighter counterparts reflect more heat from the radiation and the conduction and convection play a less significant role.
\end{abstract}

${ }^{*}$ Corresponding author: E-mail: dariusz.alterman@newcastle.edu.au; 
Keywords: Window coverings; thermal performance; effect of color; solar radiation.

\section{INTRODUCTION}

Windows in a building allow daylight to enter a building space but simultaneously they also result in heat gains and losses affecting energy balance for entire buildings. This requires an optimization of window area from the point of view of total energy demand for lighting and heating. This paper provides results of the comparative study of thermal performance of various internal window coverings between two chambers (i.e. testing and control) at the same time.

Solar-Heat-Gain-Coefficient and ThermalTransmittance (U-value) are the necessary parameters to describe the phenomenon of heat transfer through any window or window system [1-13]. Overnight, when solar radiation is absent, the U-value becomes an important parameter due to the difference in temperature between the internal and external environments. There are several techniques to determine various thermal properties of window elements and/or complete window systems, including the hot plate or Guarded Hot Box apparatus [6]; however they are determined under a steady-state environment.
From the previous research [1,2], it is known that the thermal behavior of houses is driven by the weather conditions, primarily the solar radiation, external air temperature and wall and window systems. Changes in the solar radiation throughout the day had a direct influence on the thermal behavior of the housing test modules [1]. In summer, the eastern and western walls of the modules were under the influence of a high solar altitude but the southern wall only received diffused solar radiation and the solar incidence on the north facing wall is limited. This is presented in Fig. 1.

Not all the solar radiation that was incident on the external walls was transmitted through the walls and windows into the building influencing internal environment of the modules. For example, the maximum heat flux entering the external brickwork on the western wall was approximately $200 \mathrm{~W} / \mathrm{m}^{2}$; despite the peak incident solar radiation on the same surface being of a magnitude within $700-900 \mathrm{~W} / \mathrm{m}^{2}$. However, it was $500 \mathrm{~W} / \mathrm{m}^{2}$ for the northern facing window (readings from the radiation sensors). This also highlights that a large quantity of the heat was reflected and/or radiated back to the external environment by a glass pane.

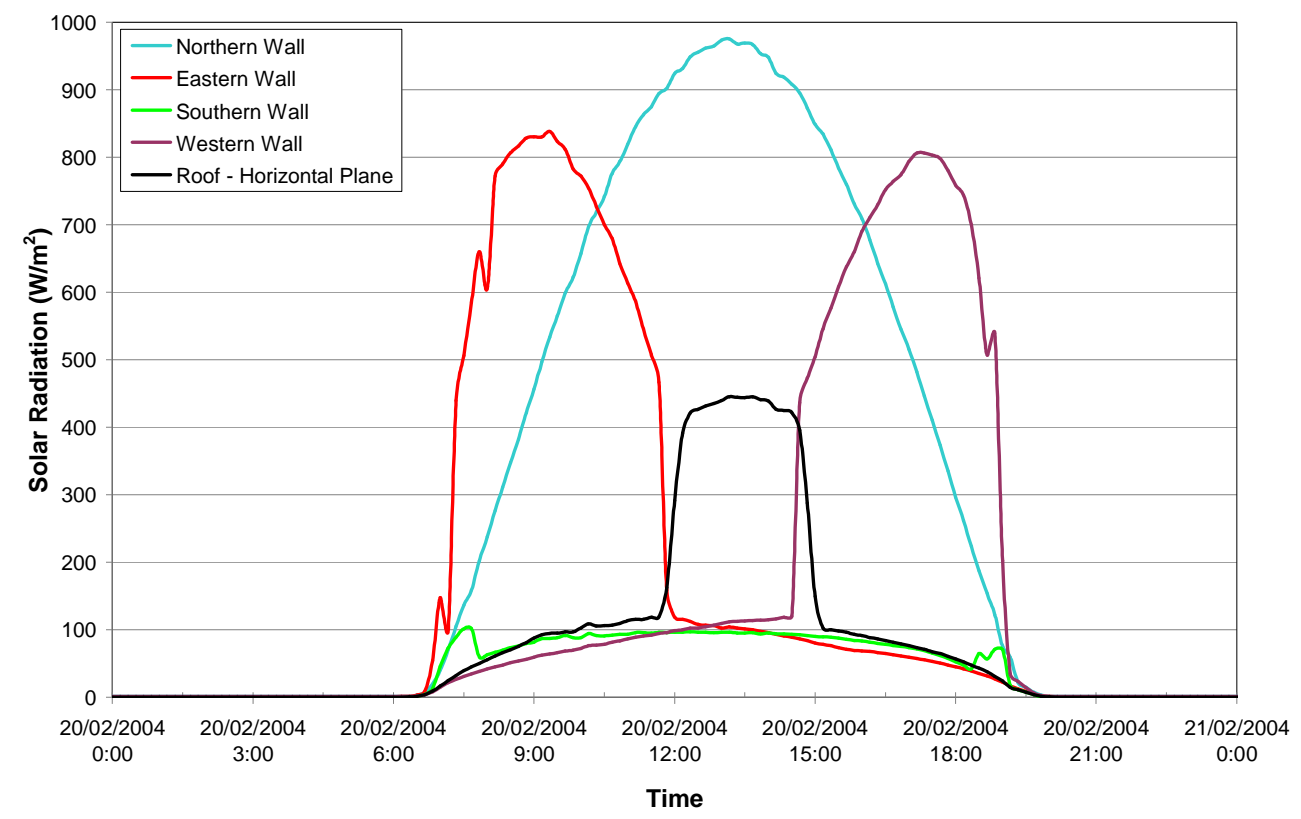

Fig. 1. The solar irradiance for external surfaces of modules on a summer day [1] Note: All solar radiation sensors were placed at mid-height of the external wall (vertical plane); the roof radiation sensor was on the horizontal plane 


\section{TESTING CHAMBERS AND SENSOR LOCATIONS}

Two identical testing chambers, one being a test chamber whilst the other a control chamber, were designed and assembled. The chambers were constructed from an aluminium frame filled with polystyrene insulation batts (R1.5) and a layer of $3 \mathrm{~mm}$ plywood. They were then covered with two layers of insulation batts of R3.5 to minimize the effect of the external environment. The dimensions of each chamber were identical, each measuring $2 \mathrm{~m} \times 1 \mathrm{~m} \times 2 \mathrm{~m}$, (see Fig. 2). The chambers were wrapped with reflective foil externally with the R0.8 insulation and covered with studio acoustic foam on the internal side of the chambers. The entire facilities were placed in an air-conditioned environment inside the test laboratory. Note: A split air-conditioning unit (Mitsubishi MSZ-GE35VA2) was set on $21^{\circ} \mathrm{C}$ during the testing duration; however, an average temperature of $22.5^{\circ} \mathrm{C}$ was measured in the middle of the test laboratory.
At the front of each chamber an identical door with a window was fitted. Both windows had the same standard $3 \mathrm{~mm}$ glass panes in a timber reveal and architraves to reproduce a standard house window; however one was fitted with a system to install various window coverings. The visible glass area of $0.5 \mathrm{~m} 2(750 \mathrm{~mm} \times 750 \mathrm{~mm})$ was chosen as $25 \%$ of the ratio of the floor relative to the window size.

At the midpoint of each chamber the aluminium posts were installed to house sensors arrays. The thermal sensors (three T-type thermocouples with accuracy of $0.5^{\circ} \mathrm{C}$ per each chamber) were positioned at $900 \mathrm{~mm}$ and 1800 $\mathrm{mm}$ at the rear of the post and $1450 \mathrm{~mm}$ (i.e. facing the window in the middle) at the front, as shown in Fig. 2. In addition, one sensor was used to monitor the external temperature. All sensors were placed on a polystyrene insulator $(60 \mathrm{~mm} \times 60 \mathrm{~mm} \times 100 \mathrm{~mm}$ ) to minimize the effect of the aluminium post.

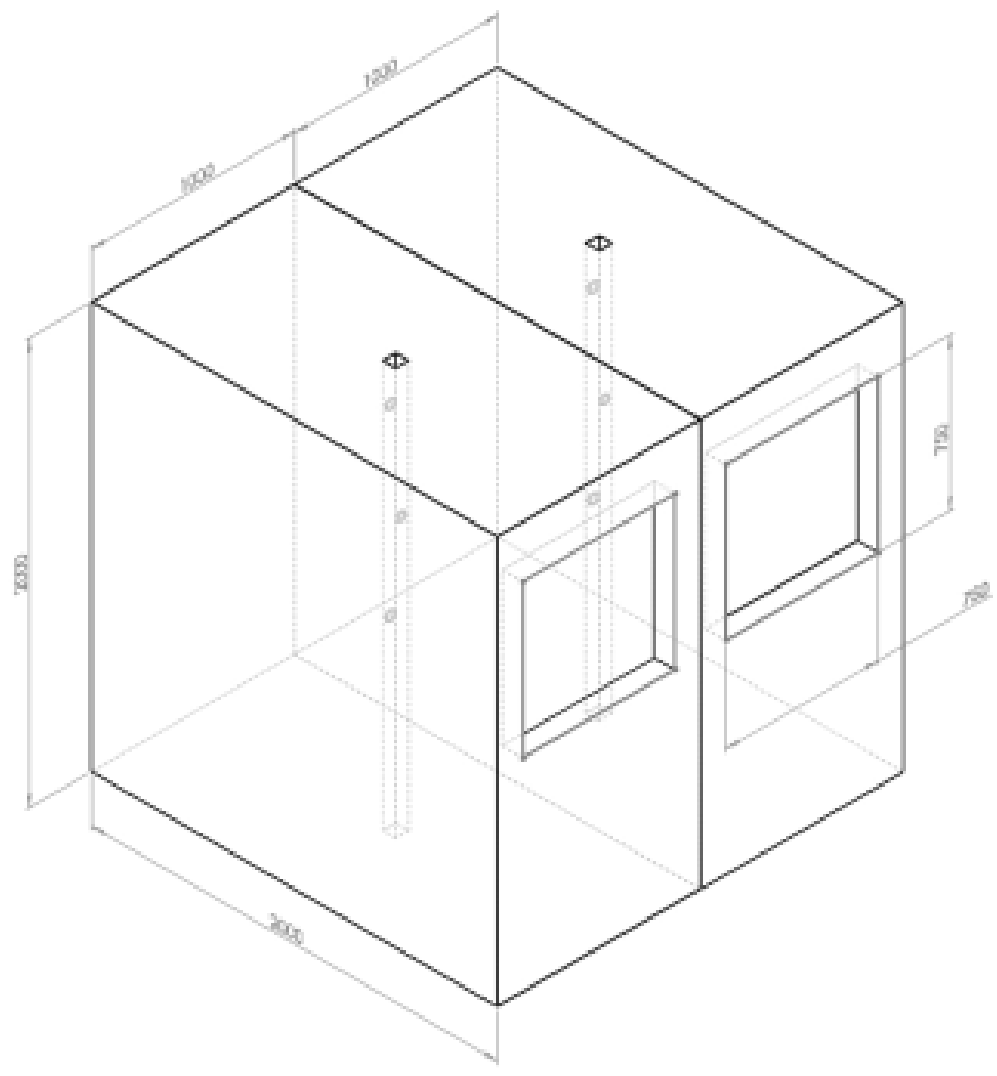

Fig. 2. Schematic chamber overview 
To reflect the peak energy of $1000 \mathrm{~W} / \mathrm{m}^{2}$ received throughout a north facing window as discussed in the Introduction section, two $500 \mathrm{~W}$ halogen lamps (one for each chamber) were installed to provide a heat source for each chamber. The lamps were fitted outside the chambers on an aluminium platform as seen in Fig. 3. Note: The halogen lamps, Plusline S 500 W R7s 1CT (color temperature of $2900 \mathrm{~K}$ and 100Ra8 color rendering index) were used.

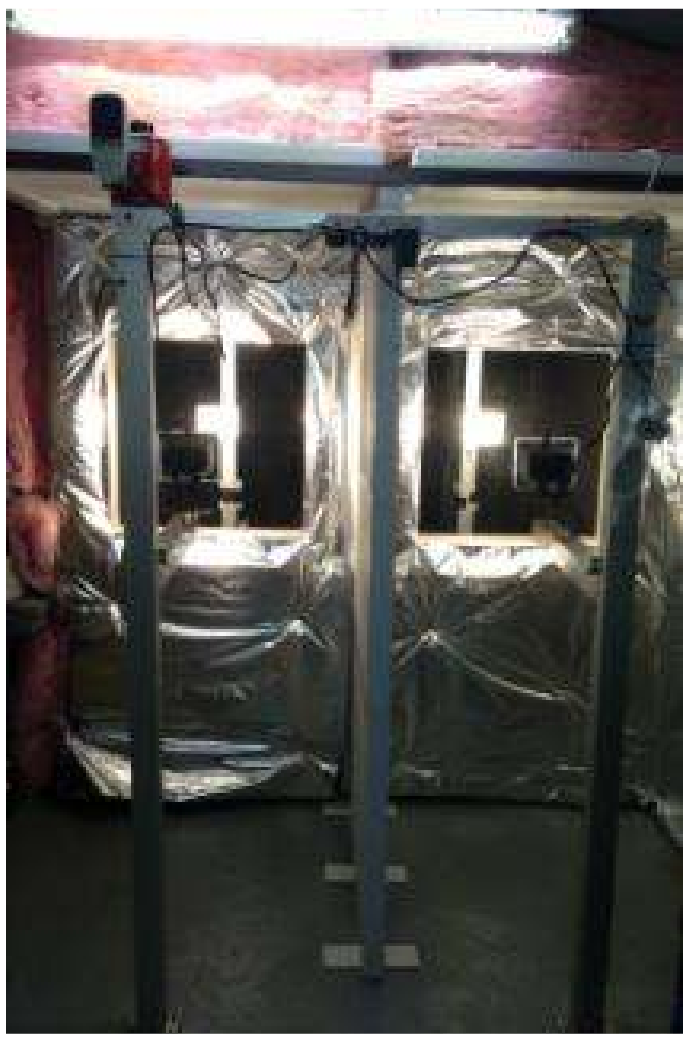

Fig. 3. Photo of chamber

The effect of heat exchange through the testing coverings was examined by the heat flux sensors $100 \times 100 \mathrm{~mm}$ with sensitivities $25 \mu \mathrm{V} / \mathrm{W} / \mathrm{m}^{2}$ installed on an aluminium plates, on the back of the internally fitted covering as shown in Fig. 4.

The thermal camera was initially used to search thermal bridges on the internal and external sides of the chambers and no major heat losses were detected. Note: Fluke Ti40 Thermal camera with a calibrated temperature range between $2^{\circ} \mathrm{C}$ and $100^{\circ} \mathrm{C}$ and thermal sensitivity of $0.09{ }^{\circ} \mathrm{C}$ was used. This therefore indicates that the effect of the external environment was minimal; however the calibration of both chambers was necessary.

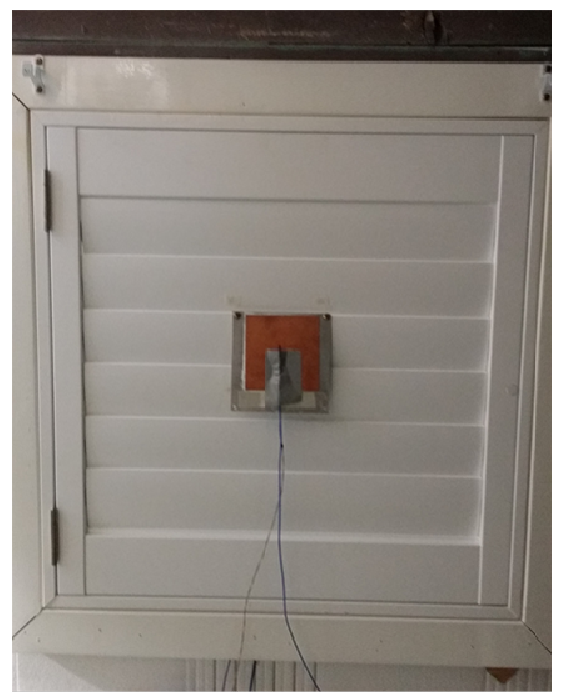

Fig. 4. Heat flux sensor fixed on back of a panel

\section{TESTING METHODOLOGY}

The major aim of the testing procedure was to experimentally study the temperature difference between the control and testing chambers (with an installed window covering) whilst both chambers were exposed to the same radiation from the accordingly adjusted light sources.

A difference of about $10 \%$ was recorded at the commencing tests due to the wall heat flow variations and orientation of the chambers. However, separate external heat sources with varied current adjustments applied to both chambers allowed the compensation of any small difference in temperature and this was attuned through the calibration procedure. The heating system was operated over a period of 9.5 hours and the datataker recorded data at 30 second intervals. At the end of each experiment, the chambers were opened to equalize their internal temperature through the air-conditioned system prior to next tests.

To equalize the temperature for both chambers, a calibration of the chambers was implemented to adjust the amount of the heat supplied to both lamps. The amended voltage of the heat sources compensated for the differences in temperature between two chambers. An average difference in temperature of $99.55 \%$ between both chambers was achieved after continuous tests. The calibration check curves for both testing and control chambers are overlayed as presented in Fig. 5. This confirms the high accuracy of the following results. 


\section{RESULTS AND DISCUSSION}

The testing procedure and methodology was applied to test the thermal performance of timber and aluminium panels in just two colors (i.e. satin white and satin black) as well as the analysis of an ultimate window covering (UWC) panel which was a polystyrene insulation panel. This was to highlight how highly conductive aluminium and low conductive timber panels of different colors responded to the same external conditions. It should be noted that the conductivity of aluminium is relatively high $(205 \mathrm{~W} / \mathrm{mK})$ and low for timber $(0.14 \mathrm{~W} / \mathrm{mK})$ and does not depend on the color. Note: The radiative properties of the surfaces (i.e. emissivity, absorptivity, reflectivity and transmittance [14] would be also beneficial for the study.

In addition, a $60 \mathrm{~mm}$ thick polystyrene insulation panel (with a thermal resistance of R1.5) with a completely sealed reveal was chosen as the ideal benchmark window covering. It was decided that the ultimate window coverings would provide a base measure as the comparison with other window coverings. The difference in air temperature profiles between two chambers (i.e. controlled and with the UWC panel) is presented in Fig. 6.

Within the first four hours, the UWC panel resisted to $80 \%$ of $1111 \mathrm{~W} / \mathrm{m}^{2}$ heat gain when compared to the controlled chamber. Even though the test was continued for over 9.5 hours (as per the testing procedures, described in Sections 2 and 3), more than $60 \%$ less heat was transferred to the testing chamber. The higher Rvalue of $3 \mathrm{~W} /\left(\mathrm{m}^{2} \mathrm{~K}\right)$ of the insulation panel might slightly provide better thermal "blockage," resisting more heat from the light source, however, the selected polystyrene panel seems to be sufficient as a reference. The polystyrene panel (UWC) performed the best difference, of $39.7 \%$, between both the chambers. The satin white panel enable a $15 \%$ better difference than the satin black panel (see Table 1).

To understand the effect of window covering materials of extreme conductivities and colors, a complex analysis was performed through employing a thermal imaging camera and heat flux sensors. The thermal photos were taken after 8 hours of continuous testing on the internal side of the panels, and are shown in Fig. 7.

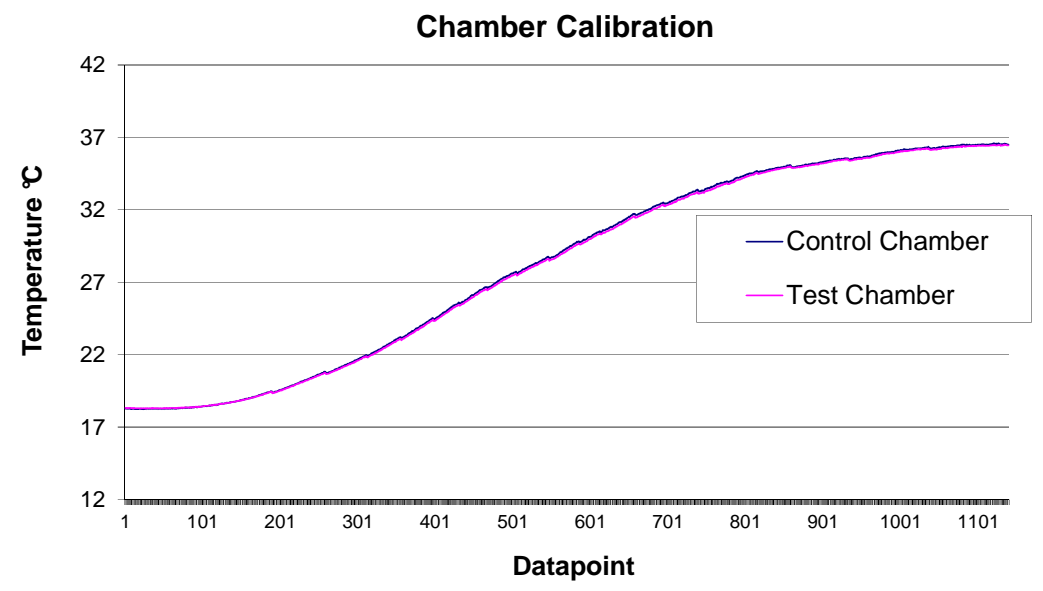

Fig. 5. Chambers calibration

Table 1. Results of thermal tests of window coverings

\begin{tabular}{|c|c|c|c|c|}
\hline \multirow[t]{2}{*}{ Window covering type } & \multicolumn{2}{|c|}{ Temperature difference [\%] } & \multicolumn{2}{|c|}{$\begin{array}{c}\text { Energy transferred through coverings } \\
{\left[\mathrm{J} / \mathrm{m}^{2}\right]}\end{array}$} \\
\hline & Satin black & Satin white & Satin black & Satin white \\
\hline UWC (R1.5) & $34.1 \%$ & $39.7 \%$ & 3456 & 1965 \\
\hline Timber panel & $18.7 \%$ & $32.1 \%$ & 5824 & 3976 \\
\hline Aluminium panel & $12.8 \%$ & $27.5 \%$ & 10212 & 4415 \\
\hline
\end{tabular}




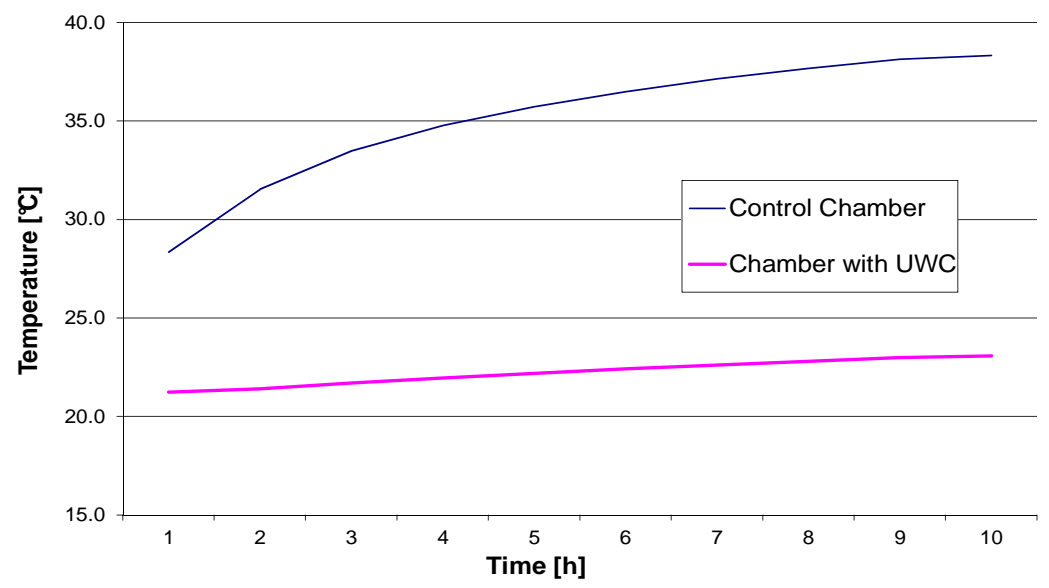

Fig. 6. Temperature profiles of UWC I
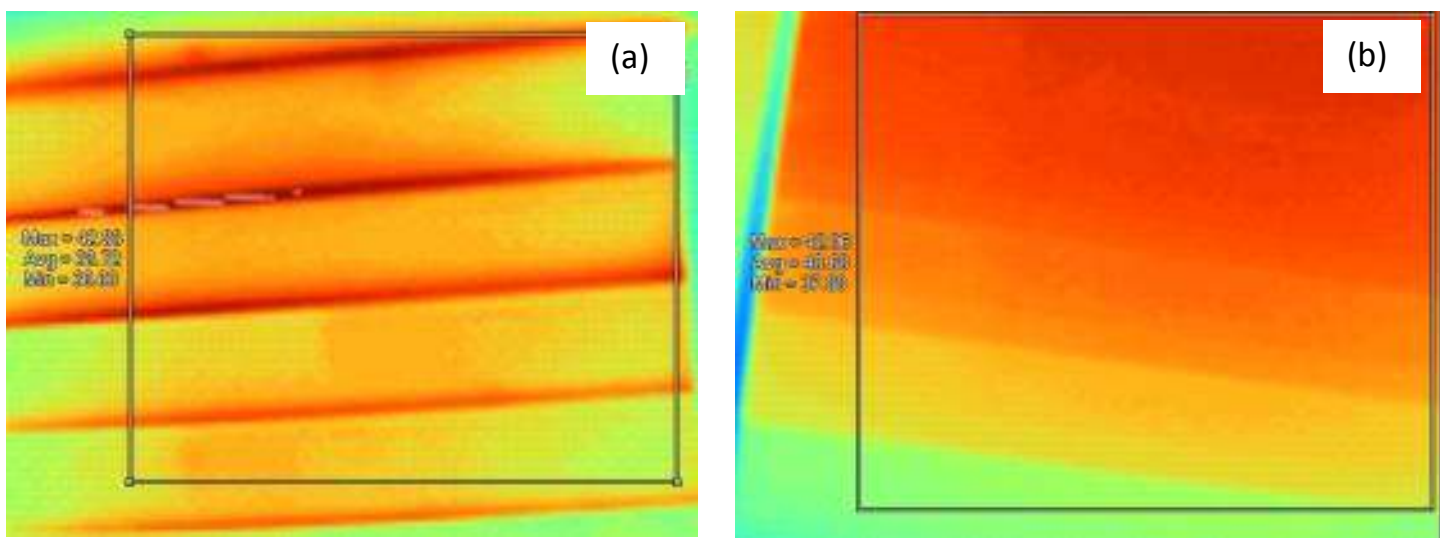

Fig. 7. Temperature distribution using a thermal camera for: (a) satin white timber panel, (b) satin white aluminium panel

The temperature distribution across the entire aluminium panel was almost uniform in comparison to the timber panel; however the temperature variation between observed extremes was lower for the aluminium panel (ranging between 38 to $42^{\circ} \mathrm{C}$ ) than the variation for the timber panel $\left(36^{\circ} \mathrm{C}\right.$ and $\left.43^{\circ} \mathrm{C}\right)$. This relatively smaller difference was not expected based on the conductivity properties alone.

The comparison tests between the testing and controlled chambers yielded similar results with a small percentage difference for the satin white panel and a much higher one for the satin black panel (Table 1). The entire behavior of each panel and its color can be explained by analysis of the heat flux profiles through the panels. This indicates how much energy was captured by the panels and later transferred by conduction to the interior of the chambers.
There is a dramatic difference in the amount of energy absorbed and transferred to the chambers due to heat absorption by the material and the effects of the color. The decrease in energy occurs progressively through the panels with almost $100 \%$ more energy passing for the satin black panels. Further analysis of the energy on the interior environment of the chambers indicated that the heat was predominately absorbed by the darker color of the aluminium panel and due to its high conductivity was quickly transferred towards the interior of the chamber, rising its temperature.

The energy movements for both timber and aluminium satin white panels upon the nature of the materials was not as obvious because only a $10 \%$ difference was recorded. This provides a good indication of the heat transfer mechanisms which are taking place. The total energy for the 
heat entering and leaving the panels depends on how much heat can be absorbed and released by the materials of the panels.

This reinforces the fact that the color of the panels plays a more important role than the material itself when the radiation is presented; the light panels reflect back more energy to the external environment than darker counterparts. This significantly lowers the amount of entrapped heat within the internal side of the chamber.

\section{CONCLUSION}

The presented procedure allowed a direct comparison of the various window coverings using testing and control calibrated chambers. The facilities and testing procedures were positively assessed and the thermal performance of various window coverings was investigated with a high accuracy.

The thermal conductivity of window covering materials is less significant because the heat can be reflected back through the window to the external environment, since the radiation is a major driver of the thermal performance. The thermal performance is then much more influenced by the color of the window coverings, as the darker panels absorb more heat on the external side of the chamber and the conduction and convection processes play a more significant role than the radiation for lighter colored panels.

\section{ACKNOWLEDGEMENTS}

The test samples were provided by Helioscreen, Markilux, Open Shutters, CW systems, Sunlight Products, Bartlett Blinds, Roman Empire and this is appreciated.

\section{COMPETING INTERESTS}

Authors have declared that no competing interests exist.

\section{REFERENCES}

1. Page AW, Moghtaderi B, Alterman D, Hands S. A study of the thermal performance of Australian Housing, Priority Research Centre for Energy, the University of Newcastle; 2011.

Available:http://www.thinkbrick.com.au/ther mal-performance-and-climate-design
2. Alterman D, Page A, Moghtaderi B, Zhang C. Contribution of thermal resistance and thermal mass to the energy demand of walling systems. Mauerwerk. 2015;19(1): 64-73.

DOI:10.1002/dama.v19.1/issuetoc.

3. Yahoda DS, Wright JL. Heat transfer analysis of a between-panes venetian blind using effective longwave radiative properties. ASHRAE Transactions. 2004; 110(1):455-462.

4. Rheault S, Bilgen E. Heat transfer analysis in an automated venetian blind window system. Journal of Solar Energy Engineering. 1989;111:89-95.

5. ISO 15099: Thermal Performance of Windows, Doors and Shading Devices Detailed calculations. International Standardization Organization; 2003.

6. ISO 10077-1, Thermal performance of windows, doors and shutters Calculation of thermal transmittance Part 1: General; 2012.

7. Huang $\mathrm{N}$, Wright J, Collins $\mathrm{M}$. Thermal resistance of a window with an enclosed venetian blind: Guarded heater plate measurements. ASHRAE Transactions. 2006;112(2):13-21.

8. Singh I, Dr. Bansal NK. Thermal and optical parameters for different window systems in India. International Journal of Ambient Energy. 2002;23(4):201-211. Available:http://dx.doi.org/10.1080/014307 $\underline{50.2002 .9674891}$

9. Pal S, Roy B, Neogi S. Heat transfer modelling on windows and glazing under the exposure of solar radiation. Energy and Buildings; 2009.

Available:http://dx.doi.org/10.1016/i.enbuil d.2009.01.003

10. Kamal MA. A study on shading of buildings as a preventive measure for passive cooling and energy conservation in buildings. International Journal of Civil \& Environmental Engineering. 2010;10(06): 19-22.

11. Wright $\mathrm{J}$, Collins $\mathrm{M}$, Huang $\mathrm{N}$. Thermal resistance of a window with an enclosed Venetian blind: A simplified model, ASHRAE Transactions. 2008;114(1):471482.

12. Arasteh D, Reilly S, Rubin M. A versatile procedure for calculating heat transfer through windows. ASHRAE Transactions. 1989;95(2). 
13. Naylor D, Lai B. Experimental study of natural convection in a window with a between- panes venetian blind. Experimental Heat Transfer. 2007;20:1-17.

14. Pierre-Olivier Logerais, Olivier Riou, Fabien Delaleux, Jean-Felix Durastanti,
Anne Bouteville. Improvement of temperature homogeneity of a silicon wafer heated in a rapid thermal system (RTP: Rapid Thermal Process) by a filtering window. Applied Thermal Engineering. 2015;77:76-89.

(C) 2015 Alterman and O'Keeffe; This is an Open Access article distributed under the terms of the Creative Commons Attribution License (http://creativecommons.org/licenses/by/4.0), which permits unrestricted use, distribution, and reproduction in any medium, provided the original work is properly cited.

Peer-review history:

The peer review history for this paper can be accessed here:

http://sciencedomain.org/review-history/11304 